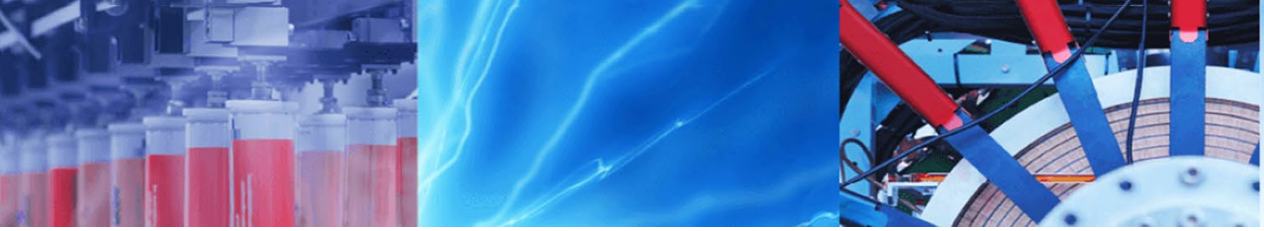

Research Article

\title{
Micro/nano-suction cup structure of silicone rubber fabricated by ArF excimer laser
}

\author{
Masayuki Okoshi ${ }^{1}$
}

() Springer Nature Switzerland AG 2019

\begin{abstract}
Micro/nano-suction cups of silicone rubber, cylindrical swelling structures in micron size with a hole of hundreds nanometer diameter each, were fabricated by $193-\mathrm{nm}$ ArF excimer laser-induced photodissociation of silicone rubber. To be periodically, silica glass microspheres of $2.5 \mu \mathrm{m}$ diameter were aligned on silicone rubber via Al thin film during laser irradiation. The Al thin film underneath each microsphere was locally laser-ablated to enable a circular irradiation of subsequent laser pulses, then the exposed silicone rubber was photochemically swelled by the photodissociation of $\mathrm{Si}-\mathrm{O}$ bonds of silicone rubber. Also, debris of aluminum surrounding the laser-ablated areas resulted in pushing microsphere up to adjust a focal point to the surface of silicone rubber to form a hole centered at each the swelled silicone. The fabricated structure showed clear superhydrophobic properties. Dependence of single pulse fluence of ArF excimer laser on the fabrication of micro/nano-suction cup structure was discussed, together with the variation of thickness of Al thin film from 10 to $100 \mathrm{~nm}$. The use of the superhydrophobic silicone rubber we fabricated is expected as a kind of delivery system, toward holding a small object even in water by each micro/nano-suction cup structure.
\end{abstract}

Keywords Micro/nano-suction cup · Silicone rubber $\cdot$ ArF excimer laser $\cdot$ Al thin film · Superhydrophobic property

\section{Introduction}

Vacuum-UV (VUV) pulsed lasers commercially available, ArF excimer laser (193 nm) and $F_{2}$ laser ( $\left.157 \mathrm{~nm}\right)$, are capable of inducing strong photochemical reactions on material surface [1, 2]. For instance, a polytetrafluoroethylene (Teflon) which is a chemically stable polymer was successfully modified into high oleophilic or hydrophilic properties by the irradiation of ArF excimer laser [1, 3-5]. As a result, the photochemically modified polytetrafluoroethylene showed high adhesion strength with an epoxy adhesives [6]. The $F_{2}$ laser also enables a unique photochemical surface modification of a polydimethylsiloxane (silicone) rubber into a pure silica glass $\left(\mathrm{SiO}_{2}\right)[2,7,8]$. Based on the modification, a $\mathrm{SiO}_{2}$ optical waveguide or $\mathrm{SiO}_{2}$ microlens array has been successfully fabricated on a flexible substrate of silicone rubber [9-12]. Also, this modification has been applied to surface hardening of silicone for developing a lightweight automobile window [13-15]. Such the VUV pulsed lasers are employed for not only the photochemical surface modifications but also materials processing by laser ablation [16-18]. In any cases, the high photon energies and thin penetration depths of material at these wavelengths are important for achieving the unique materials processing.

Recently, when the ArF excimer laser irradiated a silicone rubber, instead of $F_{2}$ laser, the photochemical swelling phenomenon which is due to the photodissociation of $\mathrm{Si}-\mathrm{O}$ bonds of silicone rubber was found on the surface $[19,20]$. Microspheres made of $\mathrm{SiO}_{2}$ in micron size were used for fabricating the periodic microswelling structure of silicone rubber, resulting in high superhydrophobic properties [21, 22]. A hydrophobic or superhydrophobic silicone is useful for industrial and biomedical applications

$\triangle$ Masayuki Okoshi, okoshi@nda.ac.jp| 'Department of Electrical and Electronic Engineering, National Defense Academy, Yokosuka, Kanagawa 239-8686, Japan.

SN Applied Sciences (2019) 1:1330 | https://doi.org/10.1007/s42452-019-1371-x

Received: 31 July 2019 / Accepted: 27 September 2019 / Published online: 4 October 2019 
$[23,24]$. As useful references, the fabrications of regular patterns on polycarbonate by ArF excimer laser are also available $[25,26]$. In the series of our work, very recently, a frusto-conical shape of the obtained microswelling structure could be changed to cylindrical by just depositing an Al thin film between microspheres and silicone rubber during laser irradiation, for the use as a micro/nanosuction cup $[27,28]$. The novelty of this work is that the successful fabrication of micro/nano-suction cup structure of silicone rubber through the ArF excimer laser-induced photochemical reactions. The structure is difficult to be realized by conventional molding process.

In this paper, to find a processing window for the fabrication of the periodic micro/nano-suction cup structure, we extend the recent experiment to the dependence of single pulse fluence of ArF excimer laser on the fabrication of the structure, together with the variation of thickness of Al thin film. An optimum condition of laser irradiation and thickness of Al thin film was derived from the present experiment, in addition to the reference to our previous work as complement data [28]. Measurement of contact angle of water was continuously carried out for realizing the superhydrophobic properties, still toward holding a small object in water as a kind of delivery system [27].

\section{Experimental procedure}

Schematic illustration of the experimental procedure is shown in Fig. 1. For the fabrication of micro/nano-suction cup structure of silicone rubber, silica glass microspheres of $2.5 \mu \mathrm{m}$ diameter (Nippon Shokubai KE-P250) were aligned on Al-deposited, 2-mm-thick silicone rubber before laser irradiation. The experimental procedure has been described in our previous work $[27,28]$. To revisit the basic concept, an Al thin film was firstly deposited on the silicone rubber by a vacuum evaporation of $\mathrm{Al}$ wire. The thickness of Al thin film was varied from approximately 10 to 50 and $100 \mathrm{~nm}$, which were measured beforehand on a slide glass using a stylus profilometer (Veeco, Dektak ${ }^{3}$ ). Then, the microspheres were dispersed in ethanol, and the dispersed solution was dripped on the Al-deposited silicone rubber. Thus, single layer of silica glass microspheres was formed on the Al-deposited silicone rubber after the heated-air drying at $50^{\circ} \mathrm{C}$ for $3 \mathrm{~min}$, together with the removal of excess microspheres.

The sample was placed $80 \mathrm{~mm}$ apart from the outlet of the ArF excimer laser (Coherent, COMPexPro110). The beam path was filled with nitrogen gas at the flow rate of $10 \mathrm{~L} / \mathrm{min}$ to avoid optical absorption of oxygen molecules (a)

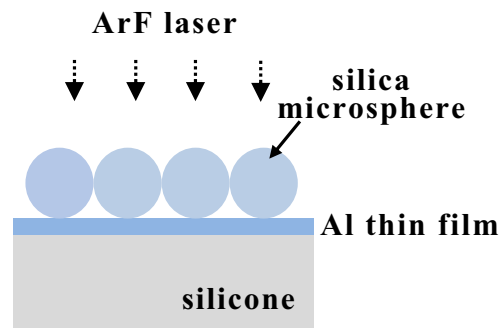

(b)

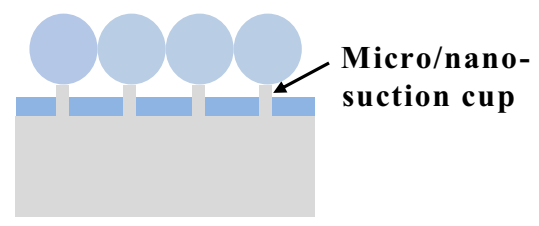

(c)

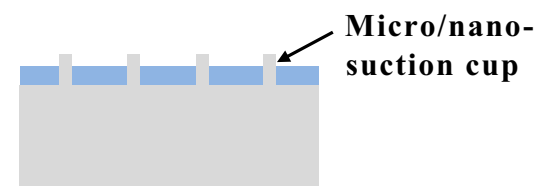

Fig. 1 Schematic illustration of the experimental procedure; a ArF excimer laser irradiation, $\mathbf{b}$ swelling of the laser-irradiated area, and c removal of silica glass microspheres

in air. A $10 \times 10 \mathrm{~mm}^{2}$ aperture was set on the outlet of the ArF excimer laser to use a homogeneous beam profile. The ArF excimer laser irradiated the sample surface without any optics. Thus, laser pulse energy was equal to the single pulse fluence. The single pulse fluence of the ArF excimer laser was changed from approximately 2 to $5,10,20$ and $30 \mathrm{~mJ} /$ $\mathrm{cm}^{2}$. The pulse repetition rate was kept constant at $1 \mathrm{~Hz}$. The pulse duration was approximately $20 \mathrm{~ns}$. The laser pulse number was changed from 15 to 60,900 and 1800 . After the laser irradiation, silica glass microspheres were removed by a $1 \mathrm{wt} \% \mathrm{HF}$ chemical etching for $90 \mathrm{~s}$ and subsequent ultrasonic washing in ethanol for $10 \mathrm{~min}$. Occasionally, remained Al thin film among the micro/nano-suction cup structure was chemically etched by a $0.5 \% \mathrm{KOH}$ aqueous solution for $30 \mathrm{~min}$.

Morphology of the sample surface was observed by a scanning electron microscope (SEM, Phenomworld, Pro). Shape of the swelling structure fabricated by laser irradiation was imaged by an atomic force microscope (AFM, Hitachi, AFM5100N). To see superhydrophobic properties of the samples, a static contact angle of water was measured. 


\section{Results and discussion}

Figure 2 shows the SEM images of the silicone rubber surfaces after ArF excimer laser irradiation and after removal of silica glass microsphere. The laser pulse number was kept at 15 . The thickness of Al thin film was approximately $10 \mathrm{~nm}$. To observe the laser-irradiated areas underneath each microsphere clearly, a subsequent chemical etching of the Al thin film was carried out by immersing the samples in the $\mathrm{KOH}$ aqueous solution for $30 \mathrm{~min}$. In the case of $2 \mathrm{~mJ} / \mathrm{cm}^{2}$ (Fig. 2a), the laser-irradiated areas in white were recognized. When the laser fluence increased to $5 \mathrm{~mJ} / \mathrm{cm}^{2}$ (Fig. 2b), circular areas of approximately $680 \mathrm{~nm}$ diameter in white were seen, together with circles of approximately $270 \mathrm{~nm}$ diameter in black. At $10 \mathrm{~mJ} / \mathrm{cm}^{2}$ (Fig. 2c), the circular areas in white was slightly expanded to be approximately $720 \mathrm{~nm}$ diameter, together with circles of approximately $270 \mathrm{~nm}$ diameter in black.

To see the structure of the laser-irradiated areas of silicone rubber, the samples shown in Fig. 2 were imaged by the AFM, as shown in Fig. 3. In the case of $2 \mathrm{~mJ} / \mathrm{cm}^{2}$ (Fig. 3a), the laser-irradiated areas slightly swelled. When the laser fluence increased to $5 \mathrm{~mJ} / \mathrm{cm}^{2}$ (Fig. $3 \mathrm{~b}$ ), the laser-irradiated areas clearly swelled. A hole centered at each the swelled silicone rubber was also observed, which is corresponding to the circle in black shown in Fig. $2 \mathrm{~b}$. A large difference between the samples at 5 and $10 \mathrm{~mJ} / \mathrm{cm}^{2}$ was not seen in the swelled structure (Fig. $3 \mathrm{c}$ ). On the other hand, the laser-irradiated areas were ablated at the fluence of approximately $20 \mathrm{~mJ} / \mathrm{cm}^{2}$ and over, as mentioned below.

Figure 4 shows the SEM images of the silicone rubber surfaces after ArF excimer laser irradiation and after removal of silica glass microsphere. In this case, the laser pulse number increased to 60 . The thickness of Al thin film was kept at approximately $10 \mathrm{~nm}$. After the subsequent $\mathrm{KOH}$ chemical etching, in the case of $2 \mathrm{~mJ} / \mathrm{cm}^{2}$ (Fig. 4a), circular areas of approximately $670 \mathrm{~nm}$ diameter in white were seen, together with circles of approximately $220 \mathrm{~nm}$ diameter in black. When the laser fluence increased to $5 \mathrm{~mJ} / \mathrm{cm}^{2}$ (Fig. 4b), circular areas of approximately $720 \mathrm{~nm}$ diameter in white were seen, together with circles of approximately $270 \mathrm{~nm}$ diameter in black. At $10 \mathrm{~mJ} / \mathrm{cm}^{2}$ (Fig. 4c), the circular areas in white was slightly expanded to be approximately $800 \mathrm{~nm}$ diameter, together with circles of approximately $350 \mathrm{~nm}$ diameter in black.

Figure 5 shows the AFM images of the samples shown in Fig. 4. In the case of $2 \mathrm{~mJ} / \mathrm{cm}^{2}$ (Fig. $5 \mathrm{a}$ ), the laser-irradiated areas clearly swelled. A hole centered at each the swelled silicone rubber was also confirmed.
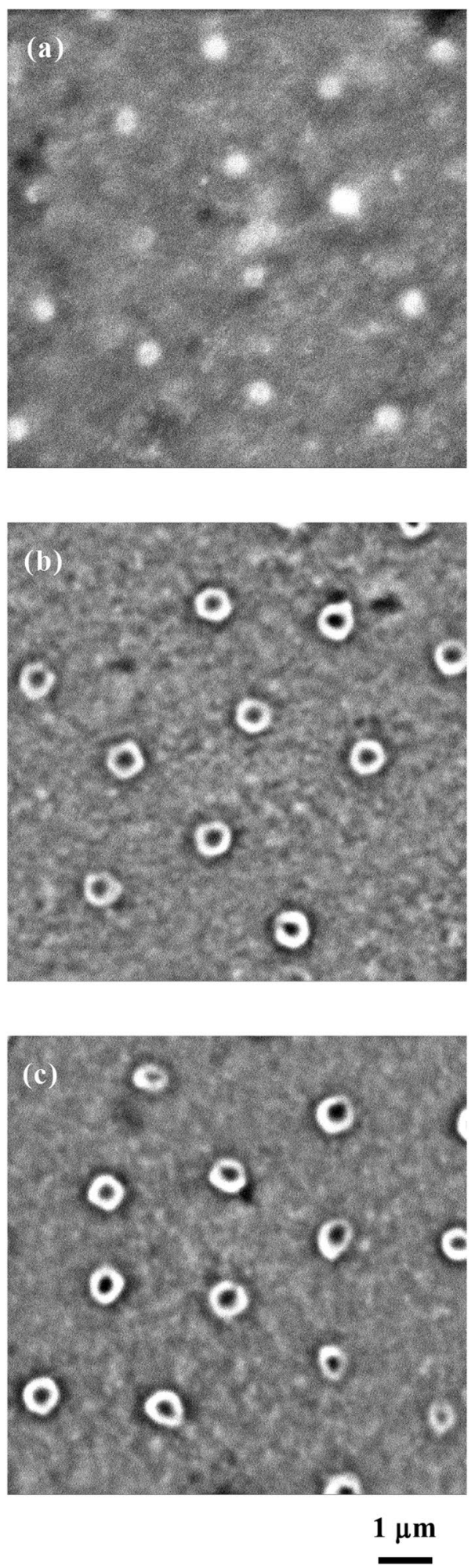

Fig. 2 SEM images of the silicone rubber surfaces after ArF excimer laser irradiation and after removal of silica glass microsphere, in addition to the subsequent $\mathrm{KOH}$ chemical etching. Thickness of $\mathrm{Al}$ thin film was $10 \mathrm{~nm}$. Laser pulse number was 15. Laser fluence was varied from $\mathbf{a} 2$ to $\mathbf{b} 5$ and $\mathbf{c} 10 \mathrm{~mJ} / \mathrm{cm}^{2}$ 

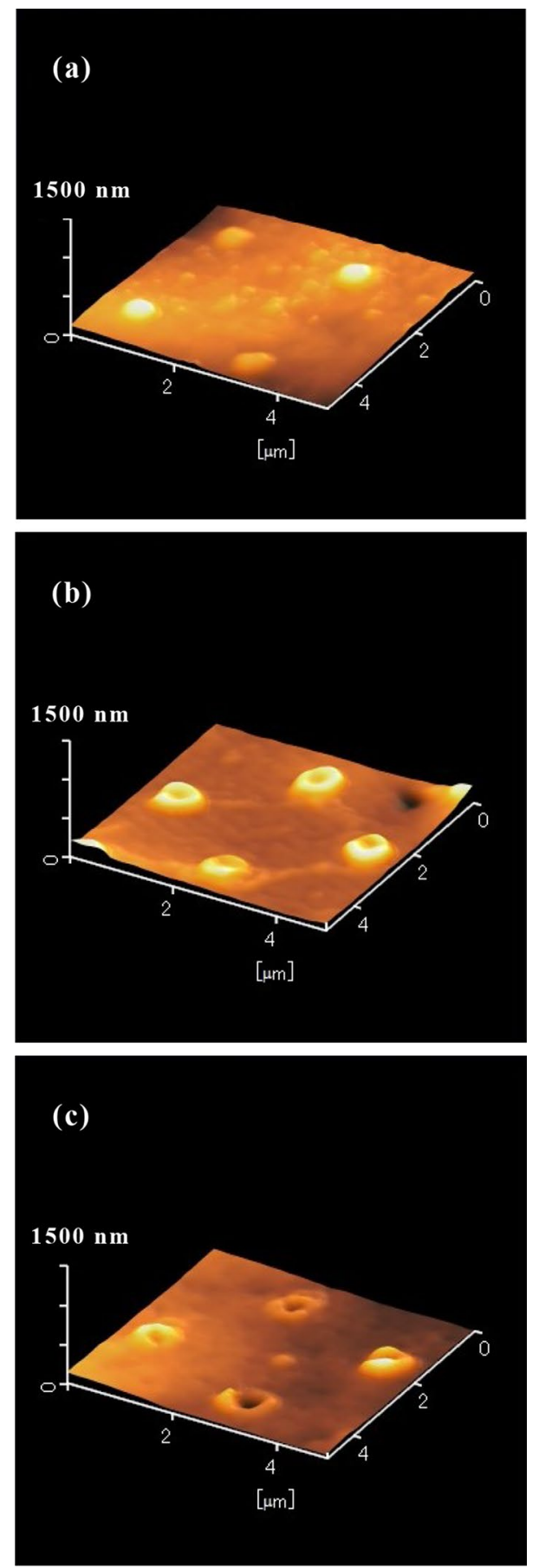

Fig. 3 AFM images of the silicone rubber surfaces after ArF excimer laser irradiation and after removal of silica glass microsphere, in addition to the subsequent $\mathrm{KOH}$ chemical etching. Thickness of $\mathrm{Al}$ thin film was $10 \mathrm{~nm}$. Laser pulse number was 15 . Laser fluence was varied from $\mathbf{a} 2$ to $\mathbf{b} 5$ and $\mathbf{c} 10 \mathrm{~mJ} / \mathrm{cm}^{2}$

When the laser fluence increased to $5 \mathrm{~mJ} / \mathrm{cm}^{2}$ (Fig. 5 b), the laser-irradiated areas clearly swelled and the height increased. At $10 \mathrm{~mJ} / \mathrm{cm}^{2}$ (Fig. $5 \mathrm{c}$ ), a hole diameter also increased clearly. Thus, the single pulse fluence of ArF
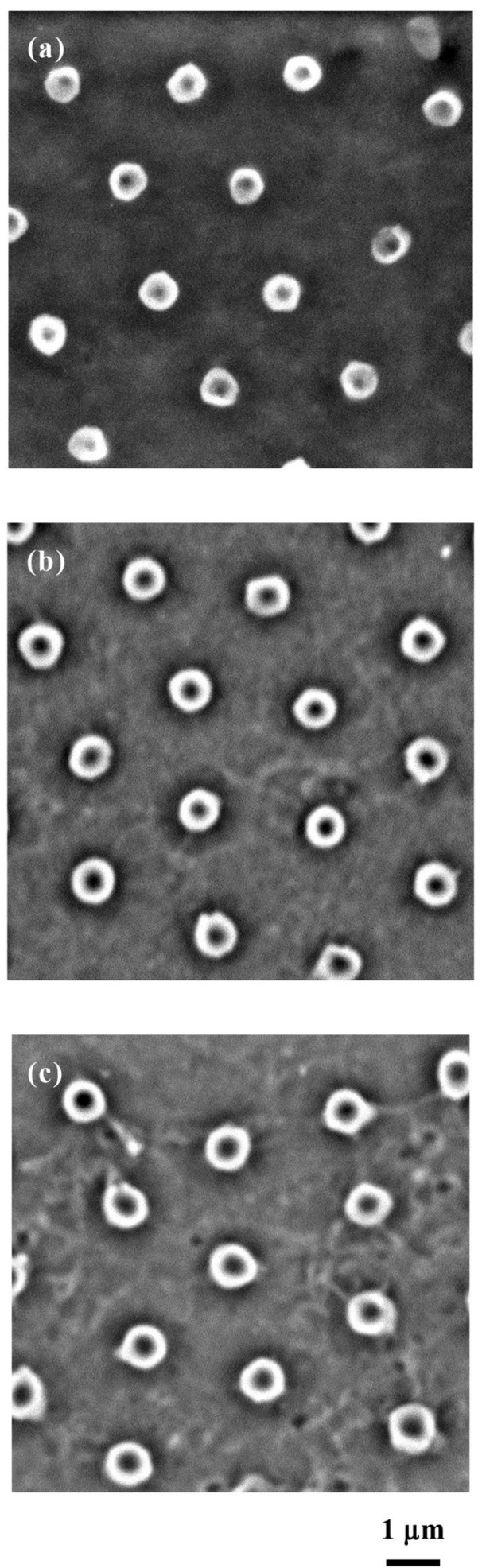

Fig. 4 SEM images of the silicone rubber surfaces after ArF excimer laser irradiation and after removal of silica glass microsphere, in addition to the subsequent $\mathrm{KOH}$ chemical etching. Thickness of $\mathrm{Al}$ thin film was $10 \mathrm{~nm}$. Laser pulse number was 60 . Laser fluence was varied from a 2 to $\mathbf{b} 5$ and $\mathbf{c} 10 \mathrm{~mJ} / \mathrm{cm}^{2}$

\section{SN Applied Sciences}



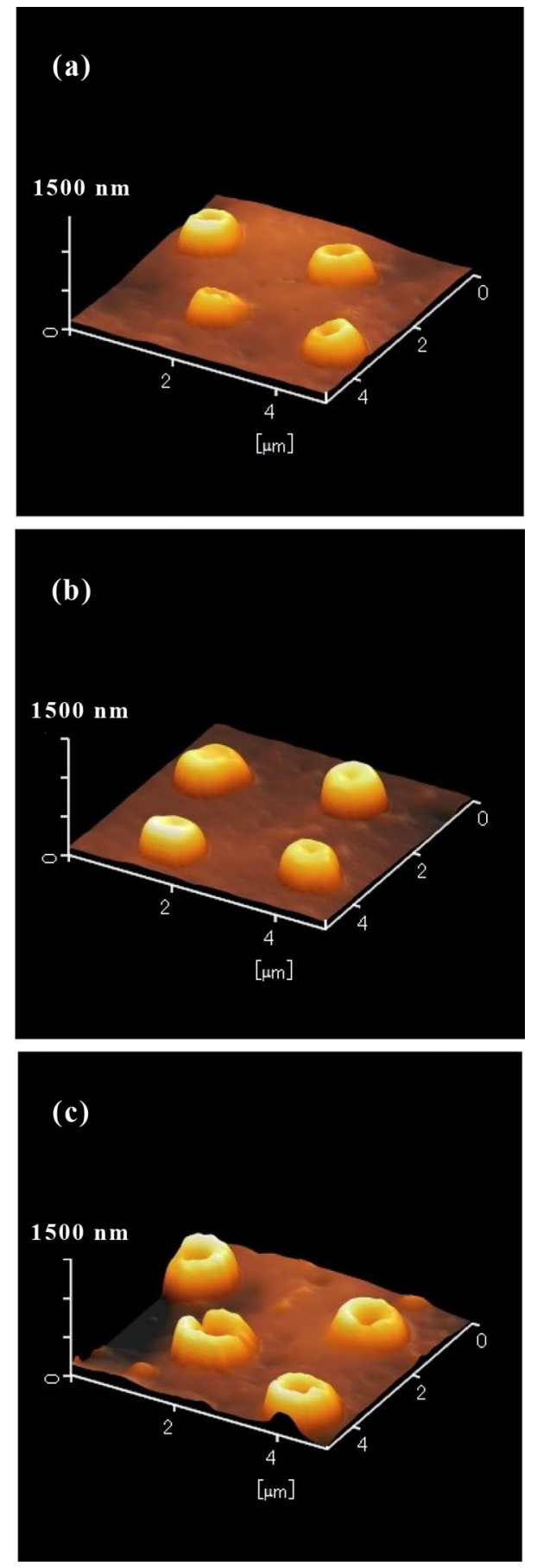

Fig. 5 AFM images of the silicone rubber surfaces after ArF excimer laser irradiation and after removal of silica glass microsphere, in addition to the subsequent $\mathrm{KOH}$ chemical etching. Thickness of $\mathrm{Al}$ thin film was $10 \mathrm{~nm}$. Laser pulse number was 60 . Laser fluence was varied from $\mathbf{a} 2$ to $\mathbf{b} 5$ and $\mathbf{c} 10 \mathrm{~mJ} / \mathrm{cm}^{2}$

excimer laser is capable of changing the diameter of the swelled structure. In addition, as the formation of the holes is based on laser ablation, the hole diameter would be changeable by varying the laser fluence. However,
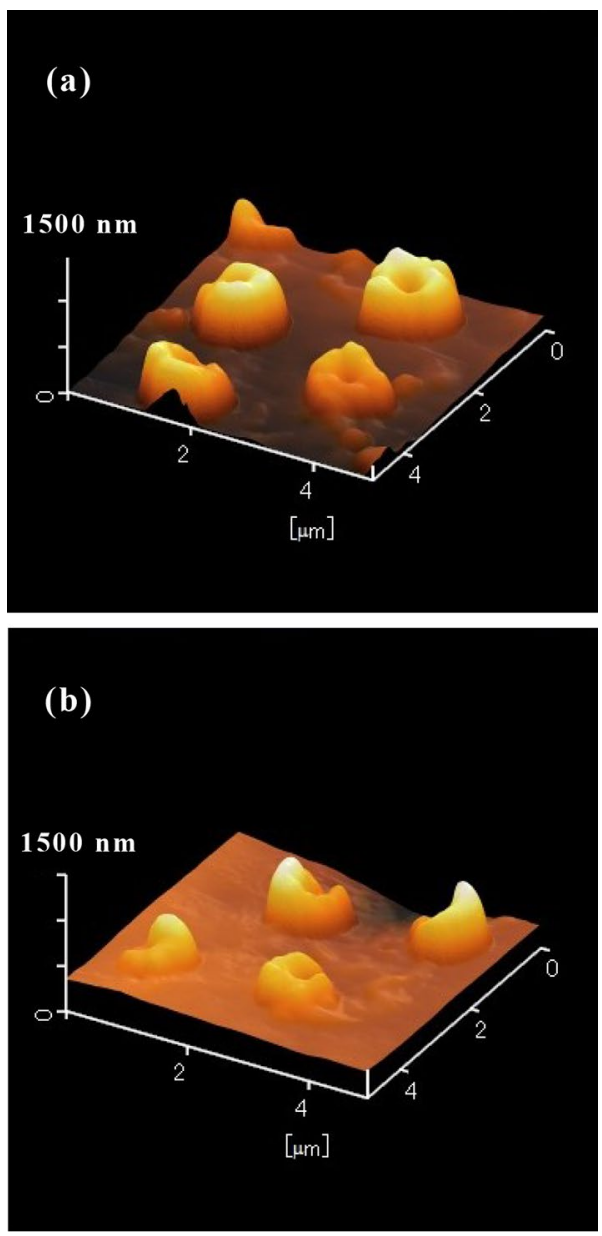

Fig. 6 AFM images of the silicone rubber surfaces after ArF excimer laser irradiation and after removal of silica glass microsphere, in addition to the subsequent $\mathrm{KOH}$ chemical etching. Laser fluence was $10 \mathrm{~mJ} / \mathrm{cm}^{2}$. Laser pulse number was 60 . Thickness of Al thin film was $\mathbf{a} 50$ and $\mathbf{b} 100 \mathrm{~nm}$

the depth of the holes in the swelling silicone cannot be measured accurately even by the AFM at this point. At the early stage of the swelling below 60 laser pulses, the diameters of swelling and hole and the height of swelling were not able to be controlled independently by changing the single pulse fluence or pulse number of ArF excimer laser.

Compared to the case in Fig. $5 \mathrm{c}$, the thickness of $\mathrm{Al}$ thin film increased from 10 to 50 and $100 \mathrm{~nm}$, as shown in Fig. 6. Again, the laser fluence and laser pulse number were $10 \mathrm{~mJ} / \mathrm{cm}^{2}$ and 60 , respectively. Judging from Fig. $6 a$, $b$, the shape of each the swelled structure became uneven by increasing the thickness of Al thin film. In our previous work, when an Al thin film was deposited on silicone rubber, the surface morphology showed a textured structure $[21,22]$. The average roughness increased with increasing the thickness of Al thin film to be roughly $40-50 \mathrm{~nm}$ [22], meanwhile the roughness of 50 and $100-\mathrm{nm}$ Al thin films 
was approximately $0.6-1.5 \mathrm{~nm}$ on a slide glass. Thus, the ablation of Al thin film caused by focusing the laser with each microsphere occurs irregularly because each the focal point becomes irregular due to the textured structure of Al thin film. In addition, when the Al thin film becomes thicker, more number of photons might be required for making the through hole of Al thin film.

Though the role of the Al thin film for forming a hole centered at each swelled silicone rubber was previously discussed [28], the understandings are briefly revisited. Qualitatively, a focal point of ArF excimer laser could be shifted to the surface side by depositing the textured $\mathrm{Al}$ thin film, resulting in exceeding a laser ablation threshold of silicone rubber at $193 \mathrm{~nm}$ wavelength. Moreover, debris of the ablated Al thin film might also push up the microsphere to move the focal point closer to the surface. Also, the change of focal point due to shockwave caused by laser ablation might be considered. As another possibility, to form the center hole, the localized ArF excimer laser heating without material removing might occur.

Figure 7 shows the SEM image of the silicone rubber surface after ArF excimer laser irradiation and after removal of silica glass microsphere. The laser fluence and laser pulse number was $10 \mathrm{~mJ} / \mathrm{cm}^{2}$ and 900 , respectively. The thickness of Al thin film was kept at approximately $10 \mathrm{~nm}$. A cylindrical structure roughly $1 \mu \mathrm{m}$ diameter and $2 \mu \mathrm{m}$ height was clearly observed at the regular intervals of approximately $2.5 \mu \mathrm{m}$.

In order to observe the swelling structures at the laser fluences of over $10 \mathrm{~mJ} / \mathrm{cm}^{2}$, the fluence was varied to 20 and $30 \mathrm{~mJ} / \mathrm{cm}^{2}$. Figures 8 and 9 show the SEM images of the silicone rubber surfaces after ArF excimer laser and

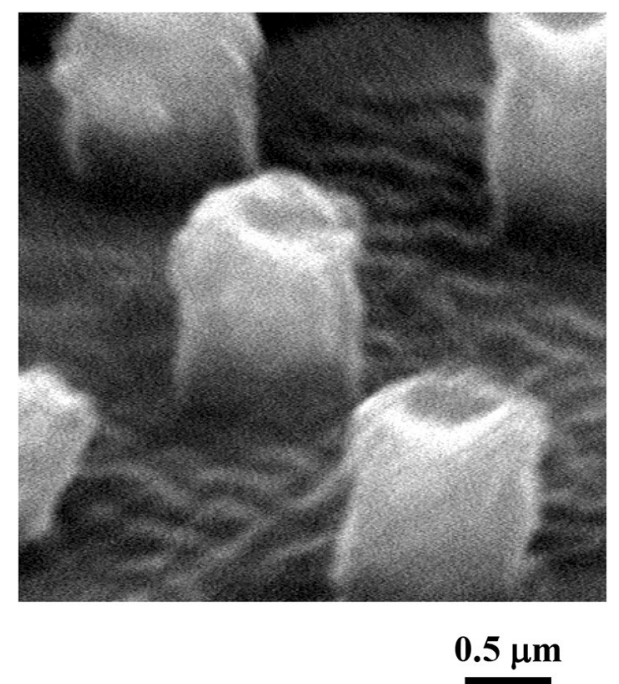

Fig. 7 SEM image of the periodic micro-suction cup structure fabricated on silicone rubber. Laser fluence was $10 \mathrm{~mJ} / \mathrm{cm}^{2}$. Laser pulse number was 900 . Thickness of Al thin film was $10 \mathrm{~nm}$
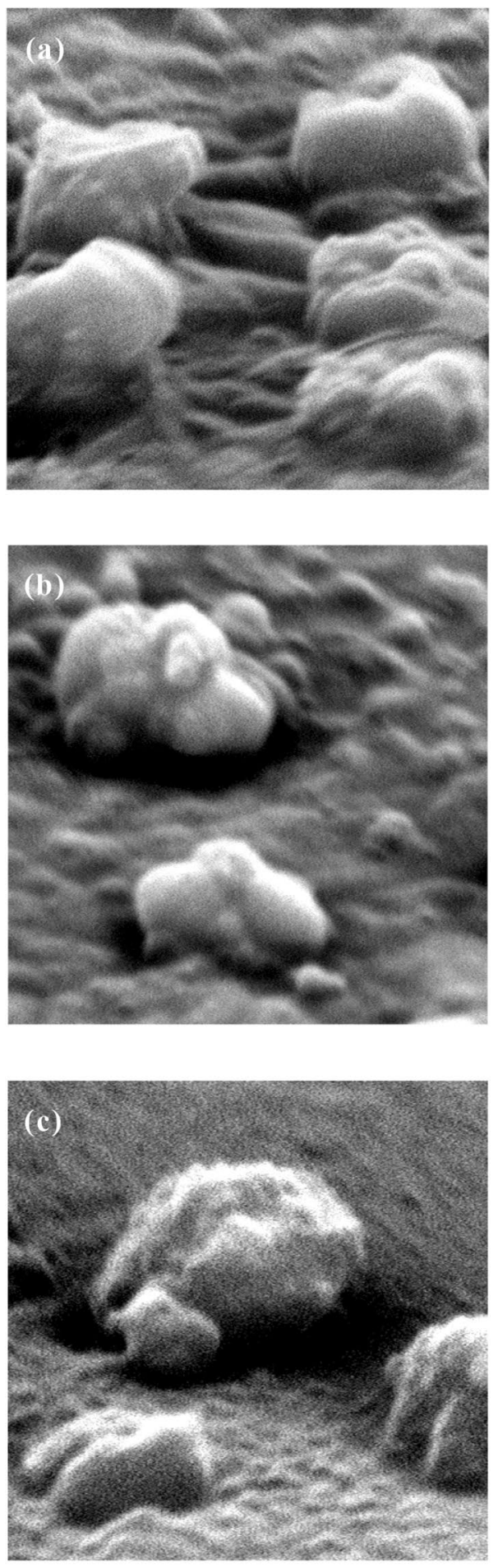

$0.5 \mu \mathrm{m}$

Fig. 8 SEM images of the silicone rubber surfaces after ArF excimer laser irradiation and after removal of silica glass microsphere. Laser fluence was $20 \mathrm{~mJ} / \mathrm{cm}^{2}$. Thickness of Al thin film was varied from a 10 to $\mathbf{b} 50$, and $\mathbf{c} 100 \mathrm{~nm}$

\section{SN Applied Sciences}



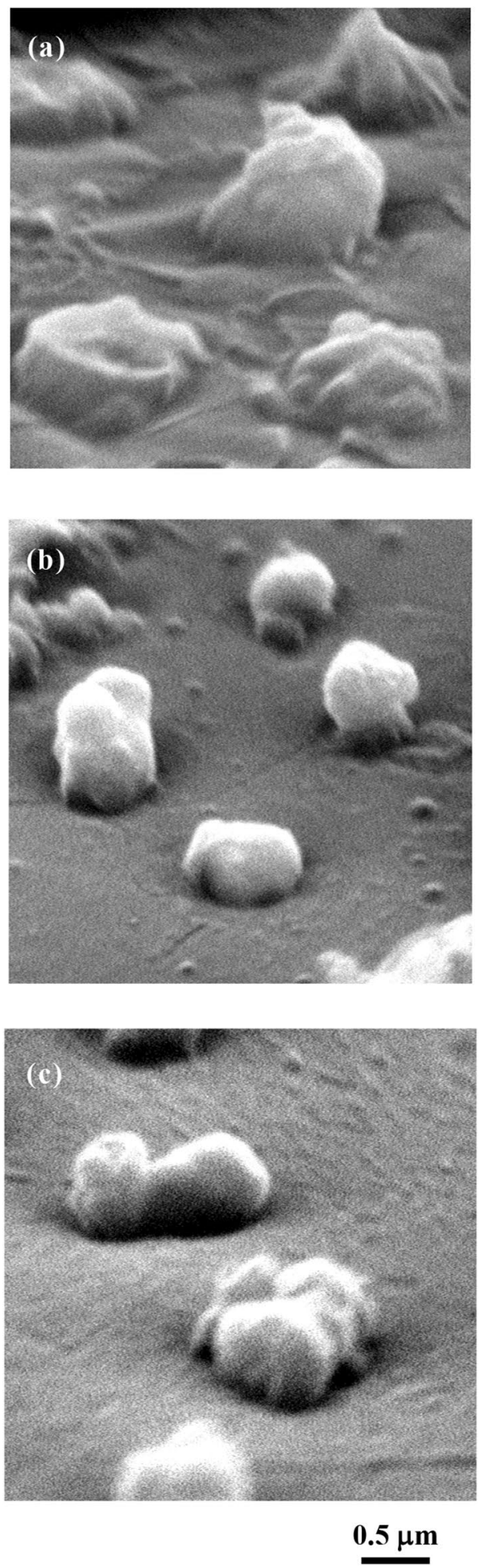

Fig. 9 SEM images of the silicone rubber surfaces after ArF excimer laser irradiation and after removal of silica glass microsphere. Laser fluence was $30 \mathrm{~mJ} / \mathrm{cm}^{2}$. Thickness of Al thin film was varied from a 10 to $\mathbf{b} 50$, and $\mathbf{c} 100 \mathrm{~nm}$

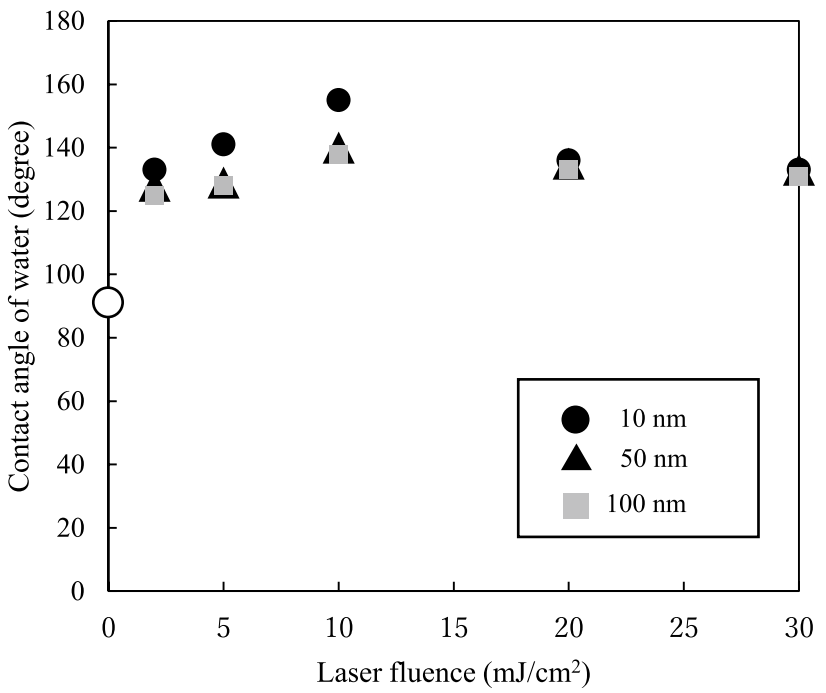

Fig. 10 Relation between the single pulse laser fluence and contact angle of water in three different thicknesses of Al thin film. Laser pulse number was 1800 in all cases

after removal of microspheres. The laser pulse number was 1800. In both cases, the swelled structures were damaged by the intense laser pulses, though the swelling was still seen. On the other hand, in our previous work [22], the cylindrical swelling structure of silicone rubber with a hole was successfully fabricated at $10 \mathrm{~mJ} / \mathrm{cm}^{2}$ fluence and at 1800 pulses, though the structure became uneven when the thickness of Al thin film was 50 and $100 \mathrm{~nm}$. Therefore, the optimum laser fluence was approximately $10 \mathrm{~mJ} /$ $\mathrm{cm}^{2}$ for fabricating the micro/nano-suction cup structure under the condition of the 10-nm Al thin film. Otherwise, at less than $10 \mathrm{~mJ} / \mathrm{cm}^{2}$, a long irradiation of ArF excimer laser could be acceptable.

Figure 10 shows the dependence of laser fluence on the contact angle of water at three different thicknesses of Al thin film, in order to evaluate the hydrophobic or superhydrophobic properties of the samples. The laser pulse number was 1800 . Measurement of contact angle of water was described in our previous work [21, 22]. In the case of a bare silicone rubber, the contact angle was approximately $90^{\circ}$. To make sure, in Ref. [19], whole surface of the periodically swelled silicones of frusto-conical shape were coated with Al thin film. On the other hand, in the present experiment, the fabricated cylindrical swelling silicones were directly contacted with a water drop when measuring the contact angle. However, the textured Al thin films were remained among the swelled silicones because the $\mathrm{KOH}$ chemical etching was not carried out. After ArF excimer laser irradiation, over $120^{\circ}$ of contact angle were obtained, which means that the fabrication of 
micro/nano-suction cup structures are easy to realize the hydrophobic properties. However, the processing window to obtain the superhydrophobic properties is narrow in the laser fluence region. To obtain the highest contact angle of water, the laser fluence of approximately $10 \mathrm{~mJ} /$ $\mathrm{cm}^{2}$ was the best at each the thickness. Especially, under the condition of 10-nm Al thin film, the superhydrophobic properties, $150^{\circ}$ and over, were successfully realized. This means that the $2 \mu \mathrm{m}$ height, regular micro/nano-suction cup structures are required for achieving the superhydrophobic properties. The use of the superhydrophobic silicone rubber we fabricated is expected as a kind of delivery system, toward holding a small object even in water by each micro/nano-suction cup structure, for fabricating a silicone-based microdevice moving in water for electronic and biomedical applications [27].

\section{Conclusions}

The cylindrical swelling structures of silicone rubber in micron size with a hole of hundreds nanometer diameter each, the micro/nano-suction cup structures, were periodically fabricated by the 193-nm ArF excimer laser. The silica glass microspheres of $2.5 \mu \mathrm{m}$ diameter were aligned on the Al-deposited silicone rubber during the laser irradiation. The Al thin film underneath each microsphere was locally laser-ablated to enable the circular irradiation of subsequent laser pulses, then the exposed silicone rubber was photochemically swelled due to the photodissociation of $\mathrm{Si}-\mathrm{O}$ bonds of silicone rubber. Also, the debris of $\mathrm{Al}$ thin film surrounding the laser-ablated areas might push the microspheres up to adjust the focal point to the surface of silicone rubber to form a hole centered at each the swelled silicone rubber. The dependence of the single pulse fluence of ArF excimer laser was examined, together with the variation of thickness of Al thin film from 10 to $100 \mathrm{~nm}$. The single pulse fluence of ArF excimer laser was capable of changing the diameter of the swelled structure. In addition, the hole diameter would be changeable by varying the laser fluence. At the early stage of the swelling below 60 laser pulses, the diameters of swelling and hole and the height of swelling were not able to be controlled independently by changing the single pulse fluence or pulse number of ArF excimer laser. The optimum single pulse fluence of ArF excimer laser was approximately $10 \mathrm{~mJ} / \mathrm{cm}^{2}$ for fabricating the micro/nano-suction cup structures under the condition of the 10-nm Al thin film. Otherwise, at less than $10 \mathrm{~mJ} / \mathrm{cm}^{2}$, a long irradiation of ArF excimer laser could be acceptable. The fabricated micro/nano-suction cup structures showed the clear superhydrophobic properties. The use of the superhydrophobic silicone rubber we fabricated is expected as a kind of delivery system, toward holding a small object even in water by each micro/nanosuction cup structure, for fabricating a silicone-based microdevice moving in water for electronic and biomedical applications.

Acknowledgements We thank Ryota Matsunaga, National Defense Academy, for valuable assistance. This work was supported by JSPS KAKENHI Grant Number JP18K04790. The corresponding author states that there is no conflict of interest.

\section{Compliance with ethical standard}

Conflict of interest The author declare that they have no competing interests.

\section{References}

1. Okoshi M, Murahara M, Toyoda K (1992) Photochemical modification of polytetrafluoroethylene into oleophilic property using an excimer laser. J Mater Res 7:1912-1916

2. Takao $\mathrm{H}$, Okoshi $\mathrm{M}$, Inoue $\mathrm{N}$ (2002) Fabrication of $\mathrm{SiO}_{2}$-humps on silicone rubber using $F_{2}$ laser. Jpn J Appl Phys 41:L1088-L1089

3. Okoshi M, Murahara M, Toyoda K (1990) Selective surface modification of fluorocarbon resin using excimer laser. Mater Res Soc Symp Proc 158:33-38

4. Okoshi M, Murahara M, Toyoda K (1991) Selective surface modification of a fluorocarbon resin into hydrophilic material using an excimer laser. Mater Res Soc Symp Proc 201:451-458

5. Okoshi M, Kashiura H, Miyokawa T, Toyoda K, Murahara M (1993) ArF laser induced photochemical substitution of $\mathrm{OH}$ radicals into Teflon surface using $\mathrm{Al}(\mathrm{OH})_{3}$ solution. Mater Res Soc Symp Proc 279:737-742

6. Okoshi M, Kashiura H, Miyokawa T, Murahara M (1994) Photochemical modification of fluorocarbon resin surface to adhere with epoxy resin. Mater Res Soc Symp Proc 334:365-371

7. Takao H, Okoshi $\mathrm{M}$, Inoue $\mathrm{N}$ (2003) $\mathrm{SiO}_{2}$ humps formed on silicone rubber by $F_{2}$ laser irradiation. Jpn J Appl Phys 42:1284-1287

8. Okoshi M, Kimura T, Takao H, Inoue N, Yamashita T (2004) Photochemical modification of silicone films using $F_{2}$ laser for selective chemical etching. Jpn J Appl Phys 43:3438-3442

9. Okoshi M, Li J, Herman PR (2005) 157-nm F $F_{2}$-laser writing of silica optical waveguides in silicone rubber. Opt Lett 30:2730-2732

10. Okoshi M, Li J, Herman PR, Inoue N (2007) Photochemical writing of silica optical waveguides in silicone rubber by $F_{2}$ laser. $J$ Phys Conf Ser 59:708-711

11. Takao H, Okoshi M, Miyagami H, Inoue N (2004) Fabrication of $\mathrm{SiO}_{2}$ microlenses on silicone rubber using a vacuum-ultraviolet $F_{2}$ laser. IEEE J Sel Top Quantum 10:1426-1429

12. Takao H, Miyagami H, Okoshi M, Inoue N (2005) Microlenses fabricated on silicone rubber using an $\mathrm{F}_{2}$ laser. Jpn J Appl Phys 44:1808-1811

13. Nojima $Y$, Okoshi $M$, Nojiri $H$, Inoue N (2010) Formation of transparent $\mathrm{SiO}_{2}$ protective layer onto polycarbonate by $157 \mathrm{~nm}$ $\mathrm{F}_{2}$ laser for lightweight automobile window. Jpn J Appl Phys 49:072703

14. Nojiri H, Okoshi M (2016) Crack suppression of silica glass formed by zoned $\mathrm{F}_{2}$ laser-induced photochemical surface modification of hard silicone thin film coating on polycarbonate. Jpn J Appl Phys 55:122701 
15. Nojiri $\mathrm{H}$, Okoshi M (2017) Surface texturing effect on crack suppression of $\mathrm{SiO}_{2}$ film formed by $\mathrm{F}_{2}$ laser-induced photochemical surface modification of silicone on polycarbonate under heat resistance test. Jpn J Appl Phys 56:085502

16. Ihlemann J, Müller S, Puschmann S, Schäfer D, Wei M, Li J, Herman PR (2003) Fabrication of submicron gratings in fused silica by $\mathrm{F}_{2}$-laser ablation. Appl Phys A 76:751-753

17. Ihlemann J, Schulz-Ruhtenberg M, Fricke-Begemann T (2007) Micro patterning of fused silica by ArF- and $\mathrm{F}_{2}$-laser ablation. $J$ Phys Conf Ser 59:206-209

18. Aesa AA, Walton CD (2018) $193 \mathrm{~nm}$ ArF laser ablation and patterning of chitosan thin films. Appl Phys A 124:444

19. Okoshi M, Pambudi WS (2016) Fabrication of superhydrophobic silicone rubber by ArF-excimer-laser-induced microstructuring for repelling water in water. Appl Phys Express 9:112701

20. Nojiri H, Pambudi WS, Okoshi M (2017) Formation of periodic micro-swelling structures on silicone rubber surface by ArF excimer laser to realize superhydrophobic property. Jpn J Appl Phys 56:072002

21. Okoshi M (2018) Fabrication of superhydrophobic silicone rubber operating in water. Appl Phys Express 11:101801

22. Okoshi M (2018) Formation of textured Al thin film on silicone rubber to obtain superhydrophobic property. SN Appl Sci 1:133

23. Owen MJ (2017) Silicone hydrophobicity and oleophilicity. Silicon 9:651-655
24. Zhong L, Jin J, Zheng D, Guan W, Guo Y, Chen A, Peng Y, Gao Q, Zheng Y, Huang H (2018) Influence of super-hydrophobic silicone rubber substrate on the growth and differentiation of human lens epithelial cells. J Mater Sci Mater Med 29:176

25. Jaleh B, Parvina P, Katoozi M, Zamani Z, Zare A (2005) Etching microscopic defects in polycarbonate due to high dose ArF or KrF laser exposure. Radiat Meas 40:731-735

26. Jaleh B, Parvinb P, Sheikh N, Zamanipour Z, Sajad B (2007) Hydrophilicity and morphological investigation of polycarbonate irradiated by ArF excimer laser. Nucl Instrum Methods Phys Res B 265:330-333

27. Okoshi M (2019) Fabrication of silicone rubber periodic microsuction cup structures using a $193 \mathrm{~nm}$ ArF excimer laser. Appl Phys Express 12:062012

28. Okoshi M (2019) Fabrication of superhydrophobic silicone rubber with periodic micro/nano-suction cup structure by ArF excimer laser-induced photodissociation. Nanomaterials 9:870

Publisher's Note Springer Nature remains neutral with regard to jurisdictional claims in published maps and institutional affiliations. 